\title{
Alcohol, illicit drugs and medicinal drugs in fatally injured drivers in Spain between 1991and 2000
}

\author{
M. Carmen del Río ${ }^{\mathrm{a}}$, Josefina Gómez ${ }^{\mathrm{b}}$, Manuel Sancho ${ }^{\mathrm{b}}$, \\ F. Javier Alvarez ${ }^{\mathrm{a}, *}$ \\ ${ }^{a}$ Drugs and Alcohol Research Group, Department of Pharmacology and Therapeutics, Faculty of Medicine, \\ University of Valladolid, 47005 Valladolid, Spain \\ ${ }^{\mathrm{b}}$ National Toxicological Centre, Instituto Nacional de Toxicología, Madrid, Spain
}

Received 9 October 2001; received in revised form 24 March 2002; accepted 12 April 2002

\begin{abstract}
The aim of this study was to assess the presence of alcohol, illicit drugs and medicinal drugs among Spanish drivers involved in fatal road accidents between 1991 and 2000. Samples were obtained for 5745 drivers killed in road accidents from January 1991 to December 2000. Of the samples, $91.7 \%$ represented males and $8.3 \%$ females; $40.7 \%$ were under 30 years of age, $31.9 \%$ were under $31-50$ years of age, $19.5 \%$ were over 51 years of age, and for $7.9 \%$ the age was unknown. Between 1991 and 2000 , some type of psychoactive substance was detected among $50.1 \%$ of those drivers killed in road accidents, this being mainly alcohol (43.8\%) and, less frequently, illicit drugs (8.8\%) and medicinal drugs (4.7\%). In all the cases, in which alcohol was detected, combined use with other substances accounted for only $12.5 \%$, whilst in the case of illicit and medicinal drugs, figures representing combined use with other substances were $75.6 \%$ for the former and $65.8 \%$ for the latter. For one in every three cases (32.0\%), a blood alcohol level over $0.8 \mathrm{~g} / \mathrm{l}$ was recorded; cocaine $(5.2 \%)$, opiates $(3.2 \%)$ and cannabis $(2.2 \%)$ were the three illicit drugs most frequently detected. Among medicinal drugs, were benzodiazepines (3.4\%), anti-depressant drugs $(0.6 \%)$ and analgesics $(0.4 \%)$. The results show the frequent presence of psychoactive substances, particularly alcohol, among Spanish motor vehicle users involved in fatal road accidents. It should be pointed out that illicit and medicinal drugs in combination with other substances were a common feature. (C) 2002 Elsevier Science Ireland Ltd. All rights reserved.
\end{abstract}

Keywords: Alcohol; Drugs; Fatal injuries; Medicinal drugs; Road traffic accidents; Spain

\section{Introduction}

Research has shown that alcohol impairs driving skills and increases crash risk [1]. Within the European Union, average yearly road traffic accidents between 1991 and 1998 involved $10,000(21.3 \%)$, out of the 47,000 fatal accidents, related to alcohol [2]. In the last years, research has shown that illicit drugs and certain medicinal drugs also impair driving skills and can increase crash risk $[3,4]$. Therefore, as drink-driving is decreasing in some countries, the role played by illicit and medicinal drugs has become the object of increasing interest $[5,6]$.

\footnotetext{
* Corresponding author. Tel.: +34-983-423077; fax: +34-983-423022.

E-mail address: alvarez@med.uva.es (F.J. Alvarez).
}

In a recent review $[7,8]$, it was shown that the presence of alcohol and drugs among injured drivers (36 and 19\%, respectively) and drivers killed on the roads (31.7 and $16.3 \%$, respectively) was a common feature. In the study conducted by Gier [9] for the Pompidou Group, Council of Europe, and based on 13 European countries, certain interesting findings were obtained. Among the general driver population, the prevalence of illicit drug use was in the range of $1-5 \%$, while that of medicinal drugs represented $5-15 \%$. Among those drivers suspected of driving under the influence of drugs, a high prevalence of medicinal drugs was reported (14-74\%), while the prevalence of illicit drugs was lower (9-57\% for cannabis, $8-42 \%$ for opiates and $1-20 \%$ for amphetamines). Regarding collision-involved drivers, the prevalence of illicit drugs ranged from 10 to $25 \%$ (in fatal road accidents) and, in the case of medicinal drugs, 
from 6 to $21 \%$. The author [9] also pointed out the difficulties encountered when comparing the different studies.

The evidence available in Spain indicates that alcohol consumption and use of other psychoactive substances are frequent among motor vehicle users, and that driving under the influence of these substances is equally customary $[10,11]$. Only in the last few years has information begun to be available about the involvement of psychoactive substances in the incidence of traffic accidents [12-14].

Current legislation in Spain states that one may not drive under the influence of psychoactive substances (illicit drugs and medicinal drugs) that may alter the physical or mental state in which one is fit to drive without danger (Royal Decree 13/1992). Likewise, maximum permissible blood alcohol levels among motor vehicle users have been established for several decades. On 7 May 1999, Royal Decree 2282/1998 became effective, establishing blood alcohol concentrations and formalising tests on motor vehicle users, as well as modifying the legislation which had been in effect until that time under the General Driving Regulations (Royal Decree 13/1992). In accordance with the new legislation, motor vehicle users are not allowed to drive if their blood alcohol concentration is greater than $0.5 \mathrm{~g} / \mathrm{l}$ ( or $0.25 \mathrm{mg} / \mathrm{l}$ in exhaled air). These limits are $0.3 \mathrm{~g} / 1(0.15 \mathrm{mg} / \mathrm{l}$ in exhaled air) for users of vehicles intended for transporting goods, passengers/school children, hazardous goods, special transportation, etc. as well as for any operator in the first 2 years after obtaining a driver's licence or permit $[12,13]$.

In this study, we analyse the data from the National Toxicological Centre regarding the presence of substances in motor vehicle drivers killed in road accidents. The aim is to determine the role that alcohol, illicit drugs and medicinal drugs play in the incidence of traffic accidents, as well as to analyse their evolution over the last 10 years (1991-2000). A preliminary version was presented at the ICADTS Conference in Stockholm [14].

\section{Material and methods}

Samples from 5745 drivers killed in road accident, from January 1991 to December 2000, were obtained. Sample distribution according to year was as follows: 1991, 259; 1992, 250; 1993, 199; 1994, 244; 1995, 279; 1996, 383; 1997,$487 ; 1998,1090 ; 1999,1191 ; 2000,1363$. A total of $91.7 \%(n=5266)$ of the samples were from males and $8.3 \%$ $(n=479)$ from females. As regards age range, $10.0 \%(n=$ $575)$ were under 20 years of age; $30.7 \%(n=1763)$ were aged $21-30$ years; $19.3 \%(n=1107)$ were aged $31-40$ years; $12.6 \%(n=726)$ were aged $41-50$ years; $8.9 \%(n=511)$ were aged $51-60$ years; $10.6 \%(n=611)$ were over 60 years of age; in the rest of the cases $7.9 \%(n=452)$, the age was unknown.

The cases correspond to samples referred to the National Toxicological Centre (Instituto Nacional de Toxicología) by forensic doctors or as instructed by the judge.
Blood samples were analysed for alcohol (ethanol) by Head-Space Gas chromatography) [12-14]. All samples were also screened for the presence of drugs other than alcohol (medicines and illicit drugs) by immunological or chromatographic methods when appropriate. The cut-off levels of the first screening were: opiates $300 \mathrm{ng} / \mathrm{ml}$; cocaine metabolite $150 \mathrm{ng} / \mathrm{ml}$; cannabinoids $20 \mathrm{ng} / \mathrm{ml}$; amphetamines 300 ng/ml; benzodiazepines $200 \mathrm{ng} / \mathrm{ml}$.

Positive results after screening were confirmed by means of gas chromatography-mass spectrometry (GC-MS), and concentrations of psychoactive drugs or metabolites were determined [12-14]. In the case of opiates, amphetamines and cocaine, the cut-off levels for the GC-MS confirmation test were in the selected ion monitoring mode (SIM) $50 \mathrm{ng} / \mathrm{ml}$, and $10 \mathrm{ng} / \mathrm{ml}$ in the case of cannabis. Positive results were confirmed by GC-nitrogen-phosphorus flame-ionisation detection (GC-NPFID) for benzodiazepines (cut-off $0.1 \mu \mathrm{g} /$ $\mathrm{ml}$ ) and for the analgesic drug dipyrone (cut-off $1 \mu \mathrm{g} / \mathrm{ml}$ ).

Substances other than alcohol were classified in two groups: illicit drugs and medicines. In the first group, categorisation into the following groups was established: opiates, cocaine, cannabis, amphetamines, synthetic drugs (ecstasy) and hallucinogenic drugs. In the second group, different sub-groups were established, in accordance with the Anatomical Therapeutic Chemical classification system.

The analytical results were expressed as follows: (i) no substance detected, or (ii) some type of substance detected. Once a substance had been detected, samples were classified in the following groups: (i) alcohol alone, (ii) alcohol plus medicinal drugs, (iii) alcohol plus illicit drugs, (iv) alcohol plus medicinal drugs plus illicit drugs, (vi) illicit drugs alone, (vii) medicinal drugs alone, (viii) illicit drugs plus medicinal drugs.

Calculation was made of the percentage referring to the cases in which alcohol, medicinal drugs and illicit drugs, as well as their possible combinations, were found. For alcohol, cases in which blood alcohol concentration was equal to, or over $0.8 \mathrm{~g} / \mathrm{l}$, and equal to, or over $0.5 \mathrm{~g} / \mathrm{l}$ for 1999 and 2000, were shown.

Between 1991 and 2000, 59,071 people were killed in road accidents in Spain (Fig. 1). The smallest number of deaths occurred in 1996 (5483) and the largest number in 1991 (6797). Within that period of time, the Spanish population changed from 38.9 million inhabitants in 1991 to 39.5 million inhabitants in 2000. As shown in Fig. 1, the number of drivers in those years increased gradually from 16.9 million in 1991 to 21.4 million in 2000. This was due to the gradual increase in the number of women obtaining a driving licence. Consequently, in 1991, 31 out of every 100 drivers were women, whereas, in 2000, the number was 35 out of every 100 .

Data analysis was conducted in the Data Processing Center at Valladolid University. Statistic analysis was by means of SAS software version 6.12 (SAS Institute SAS). An analysis of variance test (ANOVA) was employed. $P$ values $<0.05$ were considered to be significant differences. 


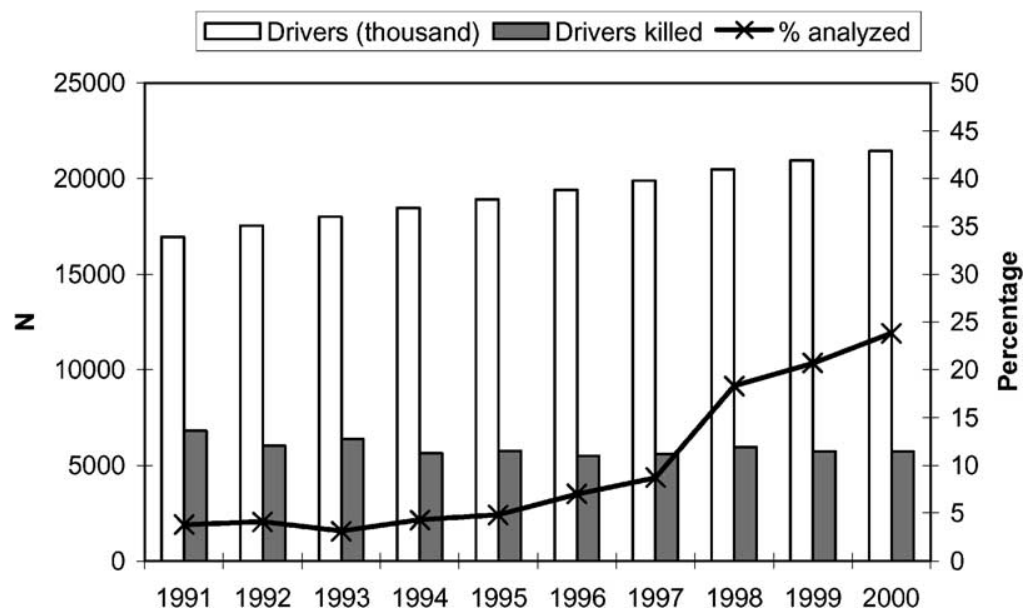

Fig. 1. Evolution of the number of drivers, of road accident victims, and analyses of fatalities in Spain between 1991 and 2000.

\section{Results}

A total of 5745 blood samples were taken from the 59,071 drivers killed in road accidents between 1991 and 2000. That is to say that the presence of substances was analysed in only $9.7 \%$ of fatal road accident cases. However, this percentage increased gradually from $3.8 \%$ in 1991 to $23.8 \%$ in 2000 (Fig. 1).

As demonstrated in Fig. 2, in 50.1\% of cases some psychoactive substance, mainly alcohol $(43.8 \%)$, was detected and, to a lesser extent, illegal drugs $(8.8 \%)$ and medicines $(4.7 \%)$. These three percentages exceeded $100 \%$, since several of these substances could be found in just one case. The mean of substances detected in positive cases is $1.19 \pm$ 0.52 (mean \pm S.D.), varying according to the presence of alcohol, illicit drugs or medicinal drugs $(F=720.62$, $P<0.0001)$.

\subsection{Alcohol}

In alcohol-detected cases $(n=2517,43.8 \%$, Fig. 2), alcohol alone was present in the majority $(n=2195$, $38.2 \%$, Fig. $2 ; 87.5 \%$ of all alcohol-detected cases). Alcohol combined with drugs was much less common $(n=230$,

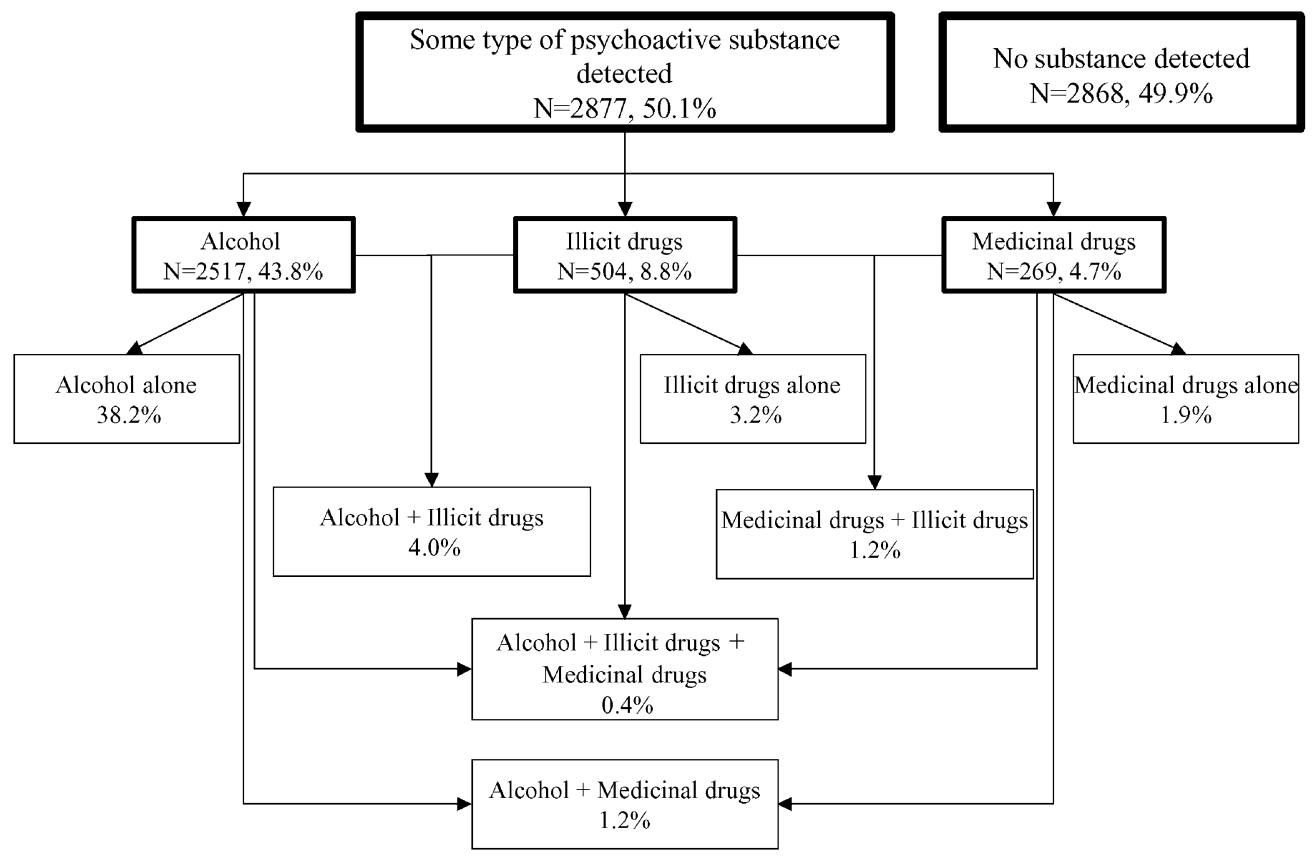

Fig. 2. Presence of substances among drivers involved in fatal road accidents, Spain, 1991-2000. 
$4.0 \%)$, followed by alcohol and medicinal drugs $(n=68$, $1.2 \%)$, and alcohol, drugs and medicinal drugs $(n=24$, $0.4 \%$ ). The mean of substances detected in those cases in which alcohol was present was $1.13 \pm 0.37$ (mean \pm S.D.).

Between 1991 and 2000, in $32.0 \%(n=1836)$ of all cases, blood concentration was higher than $0.8 \mathrm{~g} / \mathrm{l}$ (the legal limit until 6 May 1999); in other words, in nearly one in every three cases the concentration level was higher than that permitted by law. In 1999 and 2000, in 29.8\% $(n=355)$ and $32.6 \%(n=444)$ of the cases, respectively, blood concentration was found to be over $0.5 \mathrm{~g} / \mathrm{l}$ (the legal limit established from 7 May 1999).

\subsection{Illegal drugs}

Between 1991 and 2000, at least one illegal drug was detected in $8.8 \%(n=504)$ of the people killed in road accidents. In most cases, illegal drugs and substances other than alcohol were detected: in $4.0 \%(n=230)$ together with alcohol, in $1.2 \%(n=67)$ with medicinal drugs, and in $0.4 \%$ ( $n=24$ ) with alcohol and medicinal drugs (Fig. 2). That is to say, that in $63.7 \%$ (321 out of 504) of all the cases in which an illegal drug was detected, alcohol and/or medicinal drugs were also present. Moreover, with regard to the cases in which only illegal drugs were found $(n=183 ; 3.2 \%)$, at least two illicit drugs were detected in combined use in 60 of the 183 cases. In other words, two or more substances were actually present in $75.6 \%$ (381 out of 504) of the cases in which illicit drugs were found. The mean of substances detected in cases in which one illegal drug appeared was $1.86 \pm 0.62$, and this was higher than when alcohol was detected $(F=1236.15, P<0.001)$ or medicinal drugs $(F=6.21, P<0.01)$.

An analysis of the drugs detected shows that cocaine was the most common $(n=300,5.2 \%)$ followed by opiates $(n=186,3.2 \%)$, cannabis $(n=127,2.2 \%)$, amphetamines $(n=67,1.2 \%)$ and designer drugs $(n=33,0.6 \%)$.

We analysed in greater detail the cases in which cocaine was detected $(n=300)$, as it happened to be the most common drug found. As shown in Fig. 3, in $82 \%$ of the cases, cocaine was present with some other substance. In more than half of the cases cocaine was detected together with alcohol $(54.3 \%)$. Besides, cocaine was commonly found with other illicit drugs $(39.7 \%)$. The presence of cocaine with medicinal drugs was less frequent $(17.3 \%)$. Their possible combinations appear in Fig. 3.

\subsection{Medicines}

Between 1991 and 2000, medicines were detected in $4.7 \%(n=269)$ of the cases. As for the presence of other substances in combination with medicines, in $59.1 \%$ (159 out of 269) of the cases in which medicines were found, alcohol and/or illegal drugs were present (Fig. 2). In 18 out of the 110 cases in which only medicines were detected, two or more medicines were present. That is to say, that in reality

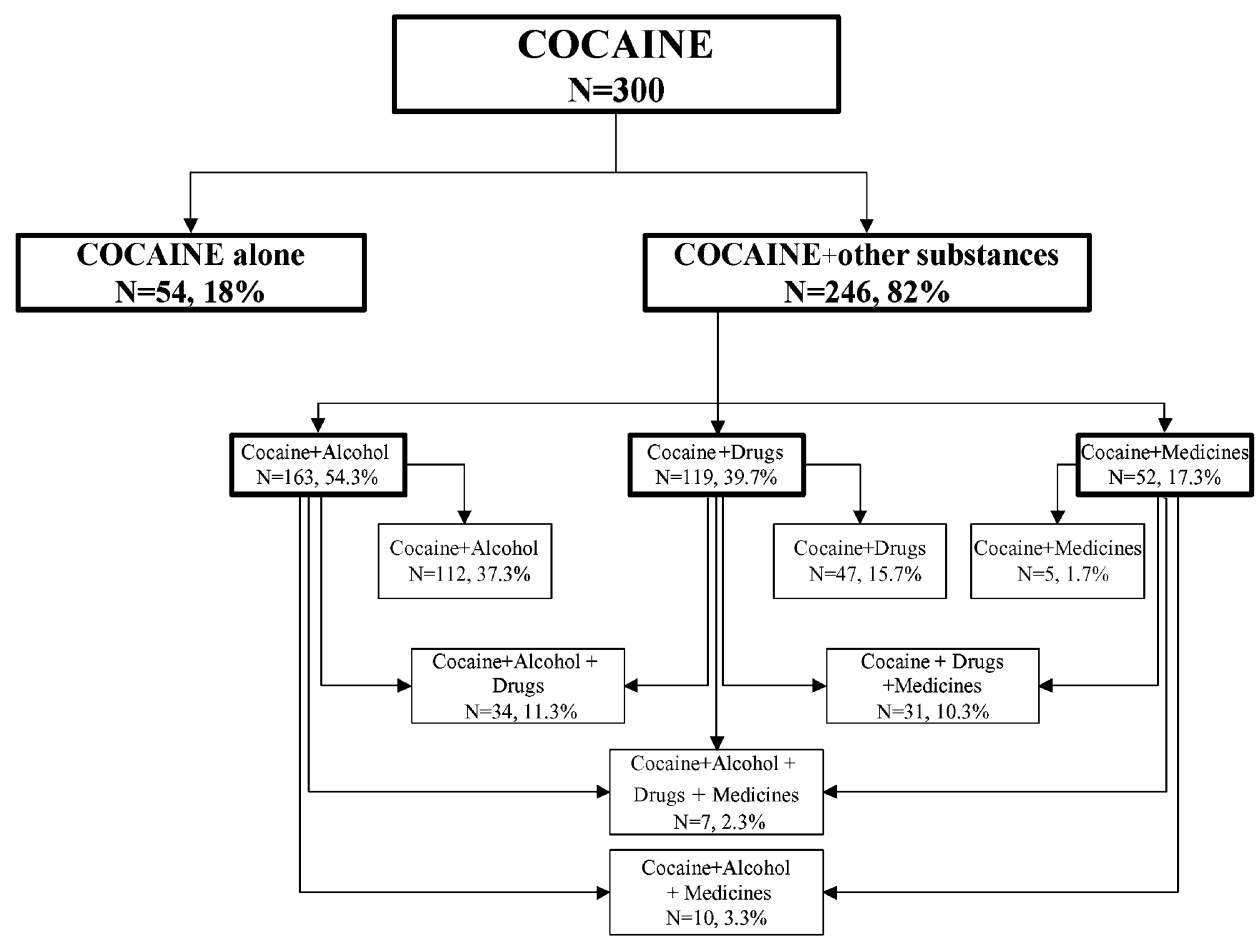

Fig. 3. Presence of cocaine among Spanish drivers involved in fatal road accidents, Spain, 1991-2000. 


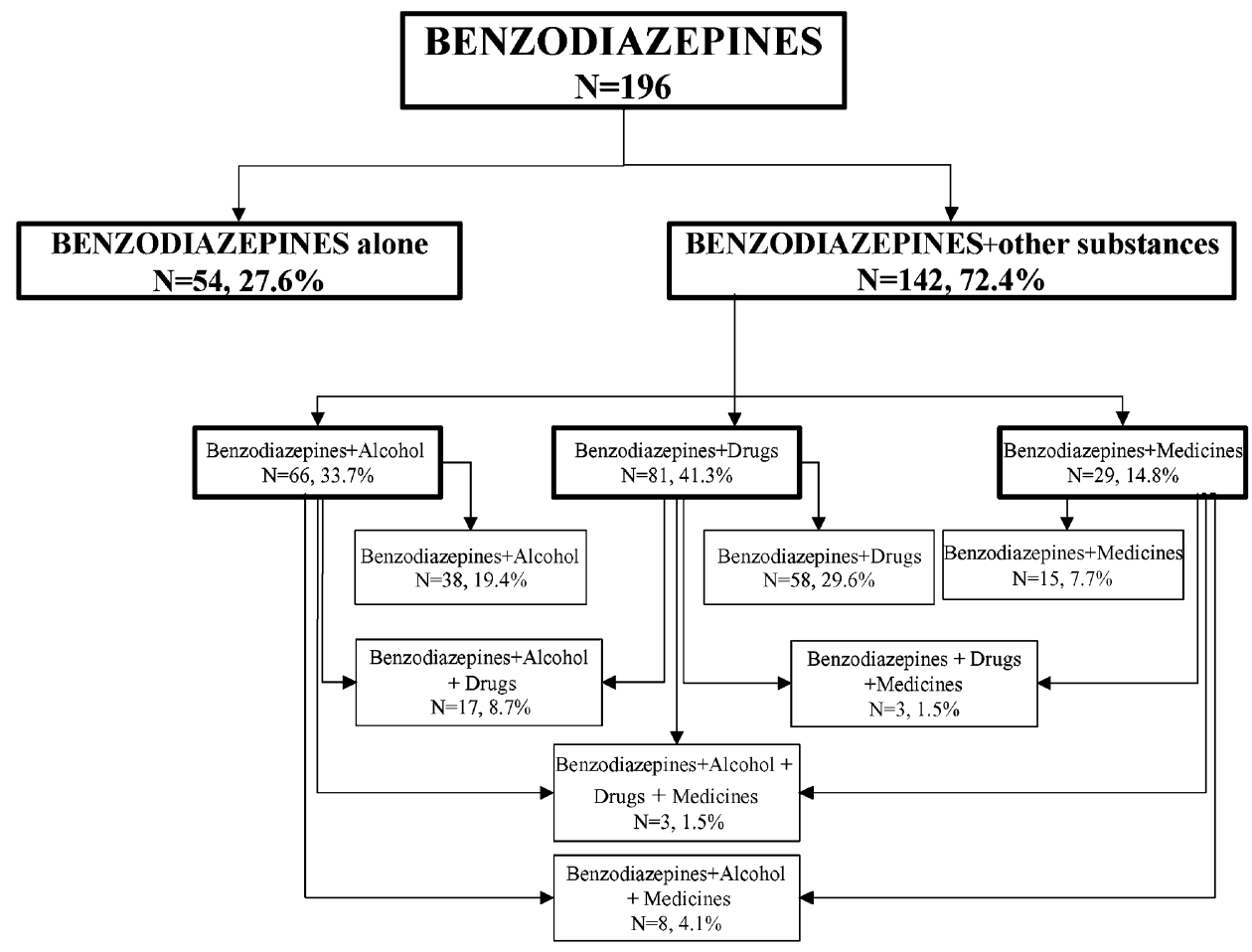

Fig. 4. Presence of benzodiazepines among Spanish drivers involved in fatal road accidents, Spain, 1991-2000.

two or more substances were detected in $65.8 \%$ (177 from 269) of the cases in which some medicine was found. The mean of substances detected in cases involving some medicinal drug was $1.74 \pm 0.60$, greater than when alcohol was detected $(F=564.96, P<0.001)$ and lower when illicit drugs were found $(F=6.21, P<0.01)$, as was mentioned above.

Benzodiazepines represented the most commonly detected group of medicines $(n=196,3.4 \%)$, followed in decreasing order by anti-depressants $(n=33,0.6 \%)$, analgesics $(n=26,0.4 \%)$, anti-epileptic drugs $(n=18,0.3 \%)$, barbiturates $(n=15,0.3 \%), \mathrm{H}-1$ anti-histamines $(n=15$, $0.3 \%)$, vasodilators $(n=9,0.15 \%)$, calcium antagonists $(n=8,0.14 \%)$, anti-hemetic drugs $(n=1,0.01 \%)$ and anti-psychotic drugs $(n=1,0.01 \%)$.

As in the case of illegal drugs, we have analysed more carefully the cases in which benzodiazepines were detected $(n=196)$, as this drug was the one most commonly traced. As may be observed in Fig. 4, in $72.4 \%$ of cases, benzodiazepines were detected together with some other substance, mainly illegal drugs (41.3\%) and alcohol (33.7\%), and less frequently, with other medicines (14.8\%).

\section{Discussion}

This study shows that the presence of substances $(50.1 \%)$ in Spanish drivers killed in traffic accidents and from whom blood samples were taken and analysed for alcohol and other drugs is by no means negligible. Although alcohol is the most commonly detected substance, the presence of illicit and medicinal drugs cannot be ignored either. Regarding alcohol, it should be pointed out that it was frequently detected (43.8\%), and that it was often over $0.8 \mathrm{~g} / \mathrm{l}$ $(32.0 \%)$. In cases in which illegal drugs $(8.8 \%)$ and medicinal drugs $(4.7 \%)$ were detected, it is noteworthy that in most cases these were found alongside other substances (75.6 and $65.8 \%$, respectively), with cocaine (5.2\%) and benzodiazepines $(3.4 \%)$ being the substances most commonly traced in relation to illicit and medicinal drugs.

In a previous study [12,13], conducted on 259 Spanish drivers killed in traffic accidents between 1994 and 1996 (randomly selected and for no legal purpose), at least one type of substance was detected in $60.0 \%$ of the cases, alcohol in $50.5 \%(\geq 0.8 \mathrm{~g} / 1$ in $35.4 \%)$, illicit drugs in $10.2 \%$ and medicinal drugs in $9.1 \%$. These figures are higher than those observed in the present study between 1991 and 2000.

Our findings show a high level of psychoactive substances in road accident victims. Nevertheless, we believe that these figures must be viewed with caution, since the number of drivers killed in whom substances were detected is very low (9.7\% of road deaths). How can this be explained? Up to 1996 (B.O.E. 23/XII/1996, pp. 3820338221) testing for alcohol (or other drugs) was not a formal requirement in Spain. As a result, the number of road 
accident victims analysed for alcohol (or other drugs) was very low. In fact, this situation was referred to colloquially as the 'widow syndrome': that is to say, no interest was shown as to whether the victim was under the influence of alcohol or not; it was preferred that the insurance companies paid the families of the victims and the incidents were forgotten. Consequently, there was always the suspicion that that tests for blood alcohol (and other drugs) concentration were carried out only in cases in which the victim showed clear signs of being under the effect of alcohol. Since 1996, the year in which the law came out, testing for alcohol has increased significantly (3.8\% in 1991 as against $23.8 \%$ in 2000), which enhances the trustworthiness of these findings.

Concerning alcohol, although comparison with data from other countries should be carefully conducted, the figures observed in our study were among the highest. In the UK [15], data accumulated from 1990 to 1994 revealed that in $45.5 \%$ of deaths alcohol was detected, and that this exceeded $0.8 \mathrm{~g} / \mathrm{l}$ in $20.25 \%$ of the victims. Recent data from 1997 [16] reveals that alcohol over $0.8 \mathrm{~g} / \mathrm{l}$ was detected in $23 \%$ of all victims. Alcohol has been frequently detected in Italy (49.0\%) [17], in France $(45.7 \%>0.7 \mathrm{~g} / \mathrm{l})$ [18] and in Belgium (28\% over $0.49 \mathrm{~g} / \mathrm{l})$ [19], whilst figures for the Nordic countries (Sweden: 27\% [20] and 20.3\% [21], Norway: $28.3 \%$ [22]) are considerably lower, perhaps as a result of the fact that in these countries there exists a very strict policy with regard to drinking and driving. High figures have also been recorded for Canada (48\%) [23] and some areas of the USA (46\%) [24-27], whereas in Australia figures are lower (36\%) [28]. Decreasing trends for drinking and driving have been observed in some industrialised countries like the USA [27].

The presence of illicit drugs $(8.8 \%)$ and medicinal drugs $(4.7 \% ; 11.9 \%$ if we consider the presence of both illicit and medicinal drugs), is lower than that mentioned in previous reviews [7-9] analysing published studies on road accident victims. Here figures of $16.3 \%$ [7,8] have been quoted when considering a combination of illicit and medicinal drugs, 10 $25 \%$ for illicit drugs, and $6-21 \%$ in the case of medicinal drugs [9]. Although the presence of illicit and medicinal drugs is much less common than that of alcohol, their importance should not be underestimated $[5,6]$.

As regards the different kinds of illegal drugs encountered, in studies carried out in various countries $[7,8]$, the most commonly found drugs have been cannabis (7.6\%), followed by opiates (3.1\%), amphetamines (1.8\%) and cocaine $(0.5 \%)$. The situation among Spanish drivers killed in road accidents is completely different: cocaine is the most frequently detected drug (5.2\%), 10.5 times more common than the mean detected in other studies [7,8], whilst cannabis was found 3.45 times less frequently $(2.2 \%)$. As regards opiates $(3.2 \%)$ and amphetamines $(1.2 \% ; 1.8 \%$ if they are considered alongside designer drugs), frequencies are similar. We can find no explanation for this greater frequency of cocaine with respect to cannabis. Although consumption frequency of the different drugs may vary between countries, drug-taking patterns are not so different among Spaniards than among other European Union citizens for these changes to be accounted for. Cannabis is the most frequently used substance in the European Union [29].

Benzodiazepines were the most commonly detected medicinal drugs $(3.4 \%)$, albeit with notably less frequency, and this-despite the fact that the use of benzodiazepines is particularly common in our country in relation to other industrialised countries [30]—corresponds with previous studies $(8.5 \%)$ [7,8].

An important point is that in most cases involving detection of illicit drugs $(75.6 \%)$ and medicinal drugs $(65.8 \%)$, at least one other substance was found alongside them; however, alcohol was detected together with another substance in only $12.5 \%$ of cases. This accounts for the high average of substances detected in cases in which some type of illegal drug (1.86) and medicinal drug (1.74) was found in relation to alcohol (1.13). The prevalence of multiple substances (alcohol, illicit drugs, medicinal drugs) used in combination is frequently reported in most of the studies [7-9,21,23,24]. The combination of various substances may bring about an increased risk of involvement in road accidents [5,6].

Drive, crash and injury characteristics among alcohol and/or drug positive cases in road traffic victims has been analysed in previous studies [21,22]. Drivers who tested positive for alcohol and/or drugs were more likely to be involved in single vehicle crash than those who tested negative. In the present study, information regarding crash characteristics was not available. We assume that the present results represent an unspecified combination of single and multiple vehicle accidents.

The figures observed in this study between 1991 and 2000 reveal that substances are regularly found in victims of road accidents in Spain. Several recent reports have made a detailed analysis of possible intervention and recommendations both in the area of drinking and driving [6,31-33] and in that of drugs (illicit and/or medicinal) and driving [5,6,34,35]. Drink-driving and drugs-driving have to be tackled in an integrated and multidisciplinary way, with the inclusion of at least stricter enforcement, tougher punishment, rehabilitation schemes, and continuous public education and publicity.

In our country, drinking alcohol forms part of many people's daily and social life, and great tolerance and permissiveness exist with regard to alcohol, thereby making intervention in this area rather difficult. However, a great effort is being made with regard to preventive policies, including, as mentioned earlier, the reduction of the legal limit.

The present study shows how widespread alcohol consumption is and reveals the high concentration level of this substance in the blood of fatally injured drivers. Although the presence of illicit and medicinal drugs is less frequent, they should, nonetheless, not be dismissed as unimportant. 
Cocaine and benzodiazepines are, respectively, the most frequent illicit and medicinal drugs detected. As reported previously [12], alcohol is the main problem in traffic fatalities in Spain, thereby making it necessary to intensify efforts and to set up specific programs to reduce drinking and driving, while also clarifying the role of drugs other than alcohol in traffic accidents.

\section{Acknowledgements}

Support for this study was provided by the National Plan on Drugs (Delegación del Gobierno para el Plan Nacional sobre Drogas) and the National Traffic Agency (Dirección General de Tráfico), Home Office (Ministerio del Interior), Madrid, Spain, as well as the Consejería de Sanidad y Bienestar Social, Junta de Castilla y León, Valladolid, Spain. We also thank Inmaculada Fierro for her technical support.

\section{References}

[1] H. Moskowitz, D. Fiorentino, A review of the literature on the effects of low doses of alcohol on driving-related skills, National Highway Traffic Safety Administration (NHTSA), Washington, DC, 2000.

[2] European Commission, Communication from the Commission to the Council, The European Parliament, The Economic and Social Committee and The Committee of the Regions: Priorities in EU Road Safety Progress Report and Ranking of Actions (COM 2000125 final), European Commission, Brussels, 2000.

[3] European Monitoring Centre for Drugs and Drug Addiction Literature review on the relation between drug use, impaired driving and traffic accidents, European Monitoring Centre for Drugs and Drug Addiction, Lisbon (CT.97.EP.14), 1999.

[4] W.J. Riedel, A. Vermeeren, M.P.J. Van Boxtel, E.F.P.M. Vuurman, F.R.J. Verhey, J. Jolles, G. Ramaekers, Mechanisms of drug-induced driving impairment: a dimensional approach, Hum. Psychopharmacol. Clin. Exp. 13 (1998) S49S63.

[5] Pompidou Group, Road Traffic and Drugs, Council of Europe, Pompidou Group, Strasbourg, 1999.

[6] Directorate General for Energy and Transport, Report on Drugs, Medicines and Driving, European Commission, Directorate General for Energy and Transport, Directorate E, Brussels, 2000.

[7] A.G. Verstraete, Which medicinal drugs impair driving performance? An overview of the European experience, in: H. Laurell, F. Schlyter (Eds.), Alcohol, Drugs and Traffic Safety T'2000, Vol. 4, ICADTS, Stockholm, 2000, pp. 12221227.

[8] A.G. Verstraete, Topic 2.2, To analyse the implication of illicit drugs in road-accidents on the basis of available data, in: Report on Drugs, Medicines and Driving, European Commission, Directorate General for Energy and Transport, Directorate E, Brussels, 2000.
[9] J.J. de Gier, Review of investigations of prevalence of illicit drugs in road traffic in different European Countries, in: Road Traffic and Drugs, Council of Europe, Pompidou Group, Strasbourg, 1999, pp. 13-61.

[10] F.J. Alvarez, M.C. Del Río, C. Prada, Drinking and Driving in Spain, J. Stud. Alcohol 56 (1995) 403-407.

[11] M.C. Del Rio, F.J. Alvarez, Illegal drugs taking and driving: patterns of drug taking among Spanish drivers, Drug Alcohol Depend. 37 (1995) 83-86.

[12] F.J. Alvarez, M.C. Del Río, Alcohol use among fatally injured drivers in Spain, Forensic Sci. Int. 104 (1999) 117-125.

[13] F.J. Alvarez, M.C. Del Río, Presence of illegal drugs in drivers involved in fatal road traffic accidents in Spain, Drug Alcohol Depend. 57 (2000) 177-182.

[14] F.J. Alvarez, M.C. Del Río, M. Sancho M, M.A. Rams, J.C. González-Luque, Alcohol and illegal drugs among Spanish drivers, in: H. Laurell, F. Schlyter (Eds.), Alcohol, Drugs and Traffic Safety T'2000, Vol. 4, ICADTS, Stockholm, 2000, pp. 357-362.

[15] G. Maycock, Drinking and driving in Great Britain-a review, Transport Research Laboratory, Berkshire, 1997.

[16] Department of Environment, Transport and the Regions (DETR), Report on Incidence of Drugs in Road Accident Victims, Interim Results of Survey, DETR, London, 1998.

[17] S.D. Ferrara, R. Giorgetti, S. Zancaner, Psychoactive substances and driving: state of the art and methodology, Alcohol and Drugs and Driving 10 (1994) 1-55.

[18] M. Deveaux, Enquête alcohol, médicaments psychotropes et opiates chez les cobducteurs et piétons impliqués dans les accidents mortels de la circulation, Observatorie Régional de Sécurité Routière, Lille, 1995.

[19] Belgian Toxicology and Trauma Study Research Group, Belgian Toxicology and Trauma Study, Ministry for Transport and Infrastructure and the Ministry for Public Health, Brussels, 1996.

[20] M. Ostrom, H. Sjogren, A. Erikson, Role of alcohol in traffic crashes involving women: passenger car fatalities in northern Sweden, J. Stud. Alcohol 56 (1995) 506-512.

[21] H. Sjogren, U. Bjornstig, A. Erikson, U. Ohman, A. Solarz, Drug and alcohol use among injured motor vehicle drivers in Sweden: prevalence, driver, crash, and injury characteristics, Alcohol Clin. Exp. Res. 21 (1997) 968-973.

[22] H. Gjerde, K.M. Beylich, J. Morland, Incidence of alcohol and drugs in fatally injured car drivers, Accid. Anal. Prev. 25 (1993) 479-483.

[23] G.W. Merced, W.K. Jeffery, Alcohol, drugs, and impairment in fatal traffic accidents in British Columbia, Accid. Anal. Prev. 27 (1995) 335-343.

[24] B.K. Logan, E.W. Schwilke, Drug and alcohol use in fatally injured drivers in Washington state, J. Forensic Sci. 41 (1996) 505-510.

[25] Insurance Institute for Highway Safety, Fatality Facts: Alcohol, Insurance Institute for Highway Safety, Arlington, 2000.

[26] R.B. Voas, J. Wells, D. Lestina, A. Williams, M. Greene, Drinking and driving in the United States: the 1996 National Roadside Survey, Accid. Anal. Prev. 30 (1998) 267-275.

[27] B.M. Sweedler, The world-wide decline in drinking and driving: has it continued, in: H. Laurell, F. Schlyter (Eds.), Alcohol, Drugs and Traffic Safety T'2000, Vol. 3, ICADTS, Stockholm, 2000, pp. 1025-1030. 
[28] O.H. Drummer, Drugs in drivers killed in Australian road traffic accidents: the use of responsibility analysis to investigate the contribution of drugs to fatal accidents, Monash University, Vic., 1994.

[29] European Monitoring Centre for Drugs and Drug Addiction, Annual Report on the State of the Drug Problem in the European Union, European Monitoring Centre for Drugs and Drug Addiction, Lisbon, 2000, also available at http:// www.emcdda.org/infopoint/publications/annrep.shtml.

[30] M.C. Del Río, F.J. Alvarez, How benzodiazepines are prescribed in a primary health care setting in Spain, Therapie 51 (1996) 185-189.

[31] European Transport Safety Council, Reducing Traffic Injuries Resulting from Alcohol Impairment, European Transport Safety Council, Brussels 1995.
[32] Dirección Générale des Transports de la Commission Européenne, L'alcohol, les drogues et les medicaments et securité routiére, Dirección Générale des Transports de la Commission Européenne, Brussels, 1995 (VII/392/ 1995).

[33] A. Clayton, Which way forward? A review of drink driving countermeasures in selected countries world-wide, The Portman Group, London, 1997.

[34] ICADTS Working Group, Illegal Drugs and Driving, International Council on Alcohol, Drugs and Traffic Safety (ICADTS), Utrecht, 2000.

[35] ICADT Working Group, Prescribing and Dispensing Guidelines for Medicinal Drugs Affecting Driving Performance, International Council on Alcohol, Drugs and Traffic Safety (ICADTS), Utrecht, 2001. 